\title{
Практика принятия инвестиционных решений в компаниях: зарубежный опыт
}

\author{
Боталова А.C. ${ }^{23}$, Емельянов А.M. ${ }^{24}$
}

В статье сделан обзор зарубежных эмпирических исследований по вопросам принятия инвестиционных решений финансовыми директорами компаний в разных странах, проводится систематизация факторов, влияющих на выбор финансовым директором того или иного показателя, а также межстрановые сопоставления.

JEL: G31

Ключевые слова: оценка инвестиционных проектов, критерии оцฺенки инвестиционных проектов

\section{Введение}

Принятие инвестиционных решений в компаниях является одной из основных задач, решаемых финансовыми директорами. Вопросу оценки инвестиционных проектов уделено достаточное внимание в учебной литературе по финансовому менеджменту или корпоративным финансам. В теоретическом плане данный вопрос является решенным. Практически все авторы предлагают принимать решения при помощи следующих инвестиционных критериев: период окупаемости (простой и дисконтированный, Payback Period, PP и DPP), бухгалтерская норма отдачи (Average Rate of Return, ARR или ROI), чистая приведенная (текущая) стоимость (ценность) проекта (Net Present Value, NPV), внутренняя норма отдачи (Internal Rate of Return, IRR), индекс отдачи (Profitability Index, PI). Данные показатели появились не одновременно. В начале прошлого века большей популярностью пользовались самые простые показатели - период окупаемости и бухгалтерская норма отдачи. Далее появились такие критерии, как NPV и IRR. На этом эволюция не остановилась: в настоящий момент появляются новые показатели (такие как EVA, CFROI), которые предлагается использовать для ряда задач, возникающих в ходе инвестиционного проектирования.

Если с теорией оценки инвестиционных проектов все ясно, то с практическими аспектами данного вопроса не все однозначно. В частности, исследования вопроса о том, какие показатели предпочитают использовать финансовые директора, начали проводиться лишь сравнительно недавно. Целью данной статьи является систематизация зарубежного опыта по проведению эмпирических исследований в области инвестиционного анализа.

\section{Показатели эффективности инвестиционных проектов, используемые зарубежными финансовыми директорами}

На настоящий день существует большое количество исследований зарубежных авторов, касающихся практических аспектов выбора финансовыми директорами тех или иных показателей эффективности инвестиционных проектов. К первым исследователям, затронувшим этот вопрос, можно отнести Пайка [Pike, 1996] и некоторых других. Однако в исследованиях анализ приверженности финансовых директоров компаний к тем или иным

\footnotetext{
23 Преподаватель кафедры финансового менеджмента, младший научный сотрудник лаборатории инвестиционного анализа Пермского филиала Государственного университета - Высшей школы экономики.

${ }^{24}$ Канд. эконом. наук, доцент кафедры финансового менеджмента, заведующий лабораторией инвестиционного анализа Пермского филиала Государственного университета - Высшей школы экономики.
} 
показателям эффективности сводился лишь к описанию выбора (иногда в динамике, в отдельно взятой стране). При этом причины того, почему финансовые директора делают тот или иной выбор, не рассматривались.

Более глубокие исследования стали появляться вслед за работой Грэхэма и Харви «Теория и практика корпоративных финансов: практическое исследование» [Graham, Harvey, 2001]. Кроме того, наиболее значимыми, на наш взгляд, являются следующие работы: Грэхэм, Харви «Как финансовые директора принимают решения о формировании инвестиционного бюджета и структуре капитала?» [Graham, Harvey, 2002]; Райан, Райан «Практика формирования инвестиционного бюджета в компаниях, входящих в рейтинг Fortune 1000: Что изменилось?» [Ryan, Ryan, 2002]; Трунг, Партингтон и Пит «Практика оценки затрат на капитал и формирования инвестиционного бюджета в Австралии» [Truong, Partington and Peat. 2005]; Силвола «Интенсивность НИОКР и экономический анализ инвестиционных решений в исследовательских фирмах» [Silvola, 2006]; Лэм, Вэнг и Лэм «Практика оценки инвестиционного бюджета в 2004 году строительными фирмами Гонконга» [Lam, Wang and Lam, 2007]; Хермес, Смид и Яо «Практика формирования инвестиционного бюджета: сравнение Нидерландов и Китая» [Hermes, Smid and Yao, 2007] и др.

В названных выше работах исследователи пытались выявить, каким показателям эффективности инвестиционных проектов отдают предпочтение финансовые директора разных стран и какие факторы оказывают влияние на этот выбор.

Анализ эмпирических исследований позволяет сделать следующие выводы о зарубежной практике использования финансовыми директорами показателей эффективности инвестиционных проектов.

В США исследование проводилось в 1999 году методом опроса на основе стандартизированной анкеты, которая была разослана финансовым директорам 4440 компаний. Однако ответы были получены лишь от 392 компаний. Таким образом, ответили лишь 9\% респондентов [Graham, Harvey, 2001].

Согласно проведенному анализу, самыми популярными методами оценки инвестиционной привлекательности проекта, применяемыми в американских компаниях, оказались критерий IRR (76\%), метод оценки NPV (75\%). В меньшей степени финансовые директора полагаются на критерий простого периода окупаемости: согласно исследованию, его используют $57 \%$ респондентов.

В Великобритании исследование проводилось в 1997 году путем анкетирования. Из 296 компаний, которым были разосланы анкеты, ответы прислали 96 участников (32\%).

Разница в популярности критериев IRR и NPV для оценки инвестиционной привлекательности проекта, применяемых в британских компаниях, также составила 1\% (81 и $80 \%$ соответственно). Метод оценки периода окупаемости применяется в 70\% компаний [Arnold, Hatzopoulos, 2000].

В Нидерландах исследование проводилось в 2003-2004 годах. Анкеты были разосланы 250 нидерландским компаниям, 42 из них прислали ответы по электронной почте [Hermes, Smid and Yao, 2007]. По результатам опроса критерий NPV в Нидерландах является самым популярным методом оценки эффективности инвестиционных проектов, критерии IRR и PBP используются нидерландскими компаниями примерно в равной степени (их используют $89 \%$ и $84 \%$ соответственно). ARR практически не используется нидерландскими компаниями - ее применяют лишь $1 \%$ респондентов.

В Канаде исследование проводилось в 1994 году. Из 588 компаний, которым были разосланы анкеты, ответили 11\% (65 компаний). Отличие исследования, проведенного в Канаде, от исследований в Великобритании и США заключается в том, что компаниям было предложено проранжировать показатели, которые они используют, по популярности. Таким образом, самым популярным критерием, используемым в канадских компаниях, оказался критерий NPV, за ним следуют IRR и PBP [Payne, Heath and Gale, 1999]. 
В Австралии исследование проводилось в 2004 году при помощи анкетирования. Анкета состояла из 20 вопросов, часть из которых была в открытой форме. Анкеты были разосланы 356 компаниям, 87 из них прислали свои ответы по электронной почте. Следовательно, ответили 24\% респондентов [Truong, Partington and Peat, 2005].

Исследование показало, что наиболее популярным критерием определения эффективности проекта является критерий NPV. Широко используется и метод определения периода окупаемости: процент использования NPV составил 94, простого периода окупаемости - 90 .

Если сравнивать данное исследование с ранее проведенными, можно сказать, что критерий NPV сохранил свои позиции как самый популярный метод оценки инвестиционной привлекательности проекта. C течением времени критерий IRR утратил преимущество перед методом оценки периода окупаемости, хотя ранее он занимал второе место по популярности [Truong, Partington and Peat, 2005].

В рамках исследования 2003-2004 годов в Китае 300 компаниям были разосланы анкеты, при этом ответы прислали 45 компаний. Исследование показало, что в Китае самыми популярными методами оценки являются критерий IRR и метод определения периода окупаемости проекта. Критерий NPV используют меньше половины китайских компаний. Критерий ARR китайскими компаниями практически не используется [Hermes, Smid and Yao, 2007].

Обобщенные сведения о проведении анкетирования, а также результаты исследований приведены в таблицах 1 и 2.

Таблица 1

Обобщенные данные об анкетировании компаний

\begin{tabular}{|l|c|c|c|c|c|c|}
\hline $\begin{array}{c}\text { Информация } \\
\text { об } \\
\text { исследовании }\end{array}$ & США & Великобритания & Нидерланды & Канада & Австралия & Китай \\
\hline Авторы & $\begin{array}{c}\text { Graham, } \\
\text { Harvey }\end{array}$ & $\begin{array}{c}\text { Arnold, } \\
\text { Hatzopoulos }\end{array}$ & $\begin{array}{c}\text { Hermes, } \\
\text { Smid, Yao }\end{array}$ & $\begin{array}{c}\text { Payne, } \\
\text { Heath, } \\
\text { Gale }\end{array}$ & $\begin{array}{c}\text { Truong, } \\
\text { Partington, } \\
\text { Peat }\end{array}$ & $\begin{array}{c}\text { Hermes, } \\
\text { Smid, } \\
\text { Yao }\end{array}$ \\
\hline $\begin{array}{l}\text { Год } \\
\text { проведения } \\
\text { исследования }\end{array}$ & 1999 & 1997 & $2003-2004$ & 1994 & 2004 & $\begin{array}{c}2003- \\
2004\end{array}$ \\
\hline $\begin{array}{l}\text { Количество } \\
\text { компаний } \\
\text { выборке }\end{array}$ & 4440 & 296 & 250 & 588 & 356 & 300 \\
\hline $\begin{array}{l}\text { Количество } \\
\text { ответивших } \\
\text { респондентов }\end{array}$ & 392 & 96 & 42 & 65 & 87 & 45 \\
\hline $\begin{array}{l}\text { Доля } \\
\text { ответивших } \\
\text { респондентов, } \\
\%\end{array}$ & 9 & 32 & 17 & 11 & 24 & 15 \\
\hline
\end{tabular}


Предпочтения финансовых директоров в использовании показателей эффективности инвестиционного проекта, \%

\begin{tabular}{|l|c|c|c|c|c|c|}
\hline & США & $\begin{array}{c}\text { Велико } \\
\text { британия }\end{array}$ & Нидерланды & Канада* & Австралия & Китай \\
\hline NPV & $75 \%$ & $80 \%$ & $89 \%$ & 1 & $94 \%$ & $49 \%$ \\
\hline IRR & $76 \%$ & $81 \%$ & $74 \%$ & 2 & $81 \%$ & $89 \%$ \\
\hline PBP & $57 \%$ & $70 \%$ & $79 \%$ & 3 & $90 \%$ & $84 \%$ \\
\hline ARR & $\begin{array}{c}\text { Нет } \\
\text { данных }\end{array}$ & $\begin{array}{c}\text { Нет } \\
\text { данных }\end{array}$ & $2 \%$ & $\begin{array}{c}\text { Нет } \\
\text { данных }\end{array}$ & Нет данных & $1 \%$ \\
\hline
\end{tabular}

* Ранг показателя.

Проведенный анализ позволяет сделать определенные выводы. Показатель NPV, который, согласно теории, является предпочтительным при оценке эффективности вложений в проект, в целом применяется наиболее часто. Вторым по популярности является критерий IRR. В таких странах, как США и Великобритания, частота использования метода чистой приведенной стоимости и метода внутренней нормы доходности практически одинакова. Оценка эффективности инвестиционных вложений в проект с использованием критерия простого периода окупаемости не является самым популярным способом ни в одной из рассмотренных стран, однако достаточно большой процент использования данного метода наблюдается в Австралии и Китае.

После проведения обобщающего анализа опыта использования финансовыми директорами разных стран тех или иных показателей эффективности инвестиционных проектов закономерно возникает вопрос о причинах их выбора.

Некоторые исследователи рассматривали зависимость использования финансовыми директорами различных показателей эффективности инвестиционных проектов от отрасли, в которой функционирует компания [Truong, Partington and Peat, 2005]. Однако исследования позволили сделать вывод, что выбор финансового директора не зависит от отраслевой принадлежности фирмы.

Влияние размера фирмы на выбор финансовыми директорами показателей эффективности инвестиционных проектов также рассматривается во многих зарубежных исследованиях [Payne, Heath and Gale, 1999; Graham, Harvey, 2001; Graham, Harvey, 2002; Ryan, Ryan, 2002; Brounen et al., 2004; Hermes, Smid and Yao, 2007]. Многочисленные результаты подтверждают гипотезу о том, что директора крупных компаний предпочитают использовать более передовые критерии эффективности инвестиционных проектов, такие как NPV и IRR. Возможно, это объясняется тем, что в крупных компаниях часто приходится принимать решения относительно масштабных проектов, и, соответственно, удельные издержки применения сложных методов NPV и IRR снижаются. Напротив, финансовые директора компаний, имеющих низкий уровень продаж, предпочитают использовать в качестве показателя оценки эффективности инвестиционных проектов критерий периода окупаемости проекта. При этом небольшое количество малых компаний использует дисконтируемый период окупаемости - метод, при котором учитывается временная стоимость денег и, таким образом, ликвидируются недостатки простого (недисконтированного) периода окупаемости.

Чем же еще можно объяснить постоянство использования финансовыми директорами малых компаний показателя периода окупаемости? Несомненно, одной из причин популярности использования этого критерия является относительная простота данного метода, а также неосведомленность высшего руководства о более сложных технологиях (в основном это характерно для директоров малых фирм). Но необходимо признать, что методика периода окупаемости может снабдить руководство полезной информацией, особенно это касается фирм с небольшим и строго ограниченным инвестиционным бюджетом. Если инвестиционный проект не предусматривает сразу положительных 
денежных потоков, компания может обанкротиться до того, как придут ожидаемые притоки средств. Даже в случае, если фирма выживет, у нее может не оказаться ресурсов для выгодных инвестиций в течение следующих двух лет. Кроме того, как считают некоторые экономисты, ответы, полученные под влиянием «сырых» практических методов, таких как период окупаемости, часто совпадают с результатами, полученными на основе более сложных методик, особенно при оценке инвестиций с высокой степенью неопределенности. А у небольших компаний «непрогнозируемых» проектов гораздо больше, чем у крупных корпораций.

Существуют исследования, которые показывают, что открытые компании используют показатели NPV и IRR чаще, чем закрытые фирмы [Graham, Harvey, 2001; Graham, Harvey, 2002; Hermes, Smid and Yao, 2007]. При этом кажущаяся очевидной взаимозависимость организационно-правовой формы компании и ее размера многими исследователями отвергается, поскольку регрессионный анализ показывает, что данные характеристики не коррелируют друг с другом [Graham, Harvey, 2002].

В основном зависимость использования финансовыми директорами показателей эффективности инвестиционных проектов от организационно-правовой формы компании связывают с тем, что для котируемых на рынке фирм легче произвести оценку стоимости капитала. Это позволяет финансовым директорам данных компаний использовать дисконтированные показатели более эффективно и правильно. В то же время в частных (закрытых) фирмах дисконтированные показатели (например, NPV) не используются, поскольку многие из этих компаний являются быстрорастущими и их инвестиционные возможности достаточно сложно определить через критерий NPV: ожидаемые денежные потоки от их инвестиций скорее всего не будут материализоваться годами.

Исследования, в которых уделяется внимание образованию финансового директора, в основном сконцентрированы на проверке гипотезы о том, что чем выше уровень образования финансового менеджера, тем ему легче использовать более надежные дисконтированные показатели [Graham, Harvey, 2001; Laitinen, 2001; Graham, Harvey, 2002; Hermes, Smid and Yao, 2007]. Выдвинутая гипотеза подтверждается различными методиками анализа: действительно, с ростом уровня образования финансового директора, дисконтированные показатели (NPV и IRR) используются чаще.

Что же касается зависимости выбора финансового директора от уровня экспорта компании в общем объеме продаж, то анализ некоторых зарубежных исследований показывает, что финансовые директора компаний, имеющих высокий уровень экспорта, предпочитают использовать дисконтированные показатели, такие как NPV и IRR [Hermes, Smid and Yao, 2007]. Доля экспорта фирмы в общем объеме продаж зачастую коррелирует с размерами фирмы и уровнем образования ее финансового директора: большинство компаний, экспортирующих свою продукцию, - это крупные фирмы, возглавляемые руководством с высоким уровнем образования.

Некоторые исследования выявили, что молодые финансовые директора компаний в большей степени используют дисконтированные показатели эффективности инвестиционных проектов, такие как NPV и IRR [Graham, Harvey, 2001]. Однако позже более современные исследования дополнили это предположение: чем моложе финансовый директор, тем выше его способность к восприятию относительно более новых методик, использующих дисконтирование [Hermes, Smid and Yao, 2007]. Анализ показывает, что на выбор финансовым директором тех или иных показателей эффективности инвестиционных проектов больше влияет размер компании, а не возраст финансового директора.

При рассмотрении влияния размера компании на выбор финансовым директором показателей эффективности инвестиционных проектов мы затронули также тему размера инвестиционного бюджета. В целом все исследователи сходятся в том, что существует положительная зависимость между размером инвестиционного бюджета и использованием дисконтированных показателей, таких как NPV и IRR. Анализ показывает, что наиболее часто компаниями с небольшим инвестиционным бюджетом используется индекс 
прибыльности (отдачи), а также критерий периода окупаемости проекта. Как уже упоминалось, зачастую размер инвестиционного бюджета компании зависит от размера фирмы в целом.

На выбор финансовым директором тех или иных показателей влияет и финансовый рычаг компании. При этом наблюдается следующая зависимость: фирмы с высокой долей заемного капитала значительно чаще используют NPV и IRR, чем фирмы с низкой долей заемного капитала (во многих исследованиях компаниями с высокой долей заемного капитала считаются фирмы, у которых показатель долга превышает 30\%). Известно, что одной из выгод использования заемного капитала является налоговый щит, а его учет происходит именно при расчете таких показателей, как NPV и IRR. Как показывают многие исследования, налоговый щит особенно важен для крупных компаний, фирм с большой долей заемного капитала, с низким уровнем риска, открытых компаний, т.е. для фирм, которые имеют тенденцию к высоким предельным ставкам налога на прибыль и, таким образом, более весомые стимулы использования заемного капитала [Graham, Harvey, 2002].

Как уровень развития страны в целом влияет на выбор финансовыми директорами компаний показателей эффективности инвестиционных проектов? Крупное исследование по данной тематике проводилось путем сравнения Нидерландов и Китая [Hermes, Smid and Yao, 2007]. Основной целью исследования являлось изучение вопроса, насколько экономическое развитие страны оказывает влияние на то, какими критериями руководствуются фирмы при принятии инвестиционного решения. Для определения значимости так называемого «странового эффекта» (country effect) использовался дисперсионный анализ, а также парный и множественный регрессионный анализы.

В ходе работы авторы сосредоточились на анализе уровня экономического развития как фактора использования того или иного метода формирования инвестиционного бюджета. Логика исследователей понятна: в более развитых странах финансовые рынки имеют гораздо более сложную структуру и высокий уровень развития человеческого капитала и технологий. Следовательно, уровень экономического развития страны и сложность методик, применяемых финансовыми менеджерами в данной стране, находятся в положительной зависимости. Центральная гипотеза исследования такова: финансовые менеджеры в более развитых странах используют дисконтированные показатели эффективности инвестиционных проектов значительно чаще, чем их коллеги в менее развитых странах.

Данные для эмпирического исследования были собраны путем проведения анкетирования. 250 голландским и 300 китайским фирмам были разосланы анкеты, в которых респонденты должны были уточнить данные относительно характеристик фирмы и финансовых менеджеров, а также ответить на три основных вопроса:

1. Какие показатели эффективности инвестиционных проектов применяются финансовым директором фирмы чаще всего?

2. Какие методы оценки стоимости капитала наиболее часто используются в компании?

3. Какие методы оценки стоимости собственного капитала являются наиболее часто используемыми в компании?

Ответы были получены от $17 \%$ голландских фирм и $15 \%$ китайских компаний. Результаты опроса показали, что голландские фирмы чаще всего применяют NPV для оценки инвестиционных проектов (89\% респондентов используют его (почти) всегда). IRR и PBP активно используются примерно одинаковым количеством фирм, a ARR гораздо менее популярен. Относительно китайских фирм результаты опроса свидетельствуют о том, что компании чаще всего используют IRR и PBP в качестве основных показателей эффективности инвестиционных проектов. Критерий NPV применяется гораздо реже, а ARR, как и в Нидерландах, практически не используется.

Проведенный исследователями регрессионный анализ позволяет сделать вывод о том, что выбор финансовыми директорами показателя NPV в качестве критерия оценки эффективности инвестиционных проектов зависит от «странового эффекта»: китайские 
фирмы применяют данный критерий значительно реже, чем голландские. При этом зависимость сохранялась и после ввода в рассмотрение контрольных переменных. Таким образом, исследования доказали, что использование критерия NPV зависит от уровня экономического развития страны.

Выбор показателя IRR в качестве метода оценки эффективности инвестиционных проектов не так сильно зависит от «странового эффекта»: коэффициент данного фактора в парной модели значим только на уровне $10 \%$, а при введении контрольных переменных становится незначимым. Отсутствие различий между странами в применении подобного критерия авторы объясняют тем, что голландские фирмы все чаще начинают использовать метод NPV, который более корректен, чем IRR, а в китайских фирмах критерий IRR еще не получил должного распространения. Использование критерия ARR более свойственно китайским фирмам, нежели голландским. Это подтверждает и парная, и множественная регрессионные модели.

Таким образом, исследователи пришли к следующему выводу: уровень экономического развития страны влияет на выбор финансовыми директорами компаний показателей эффективности инвестиционных проектов. B развитых странах чаще применяются дисконтированные показатели NPV и IRR (при этом использование IRR в последнее время сокращается). В развивающихся - финансовые директора отдают предпочтение такому критерию, как PBP; показатель IRR уже приобрел некоторую известность, но еще широко не используется.

\section{Заключение}

Выбор финансовым директором приоритетных показателей эффективности инвестиционного проекта имеет огромное значение для фирмы, поскольку инвестиционные решения оказывают большое влияние на максимизацию благосостояния собственников. С научной точки зрения существует несколько методов или критериев оценки эффективности инвестиционных проектов, которые делят на дисконтированные и недисконтированные. С теоретической точки зрения дисконтированные показатели являются наиболее правильными и точными критериями оценки проекта. Однако они же и наиболее сложны для расчета, поскольку для их определения необходимо построить денежные потоки и выбрать ставку дисконтирования. Использование недисконтированных методик зачастую приводит к большому количеству неточностей и ошибок, при этом применение данных показателей характеризуется легкостью и понятностью расчетов, в особенности это касается критерия простого периода окупаемости.

Эмпирические исследования по принятию инвестиционных решений начали появляться в конце 1990-х годов. Рассмотрение исследований в динамике свидетельствует о том, что со временем фирмы предпочитают использовать более сложные дисконтированные критерии оценки инвестиционных проектов. В развитых странах наблюдается тенденция к усложнению методов оценки инвестиционных проектов, однако европейские фирмы в меньшей степени ориентированы на дисконтированные методики, нежели их коллеги из США [Brounen et al., 2004]. В развивающихся странах недисконтированные методы остаются наиболее популярными и на настоящий день, несмотря на то что число компаний, использующих NPV или IRR, неуклонно растет.

Что же касается взаимосвязи выбора финансовыми директорами компаний тех или иных показателей эффективности инвестиционных проектов и некоторых условий (факторов), то обзор зарубежного опыта позволил выявить следующие основные закономерности. Исследования показали, что на выбор показателей влияет размер компании, ее организационно-правовая форма, уровень образования финансового директора, принимающего решения об инвестировании, финансовый рычаг компании. Кроме того, на использование тех или иных показателей эффективности инвестиционных проектов оказывает влияние размер инвестиционного бюджета компании, доля экспорта компании в 
общем объеме продаж, возраст финансового директора. Однако над этими факторами доминирует влияние размера компании. Другими словами, последние факторы коррелированы с размером фирмы: крупные компании - это зачастую фирмы, экспортирующие часть своей продукции, располагающие крупным инвестиционным бюджетом и возглавляемые опытным руководством с высоким уровнем образования.

Нельзя однозначно утверждать, что выбор показателей эффективности инвестиционных проектов зависит от уровня экономического развития страны, поскольку исследований, посвященных этой теме, еще недостаточно. Более того, есть работы, авторы которых не заявляют о несомненном наличии данной закономерности. Таким образом, необходимо дальнейшее исследование данного вопроса с участием большего количества компаний из разных стран.

Важно отметить, что в настоящее время исследования, анализирующие выбор показателей эффективности инвестиционных проектов российскими финансовыми директорами, не проводились. Следовательно, данное направление может стать перспективным для дальнейшей работы.

\section{Список литературы}

1. Arnold, G., Hatzopoulos, P. (2000), The theory-practice gap in capital budgeting: Evidence from the United Kingdom, Journal of Business Finance and Accounting, 27(5) (2000) 603626.

2. Brounen, D., De Jong, A., Koedijk, K. (2004), Corporate finance in Europe: Confronting theory with practice, Financial Management, 33(4) (2004) 71-101.

3. Graham, J., Harvey, C. (2001), The theory and practice of corporate finance: Evidence from the field, Journal of Financial Economics, 60 (2001) 187-243.

4. Graham, J., Harvey, C. (2002), How do CFOs make capital budgeting and capital structure decisions?, The Bank of America Journal of Applied Corporate Finance, 15(1) (2002) 8-23.

5. Hermes, N., Smid, P., Yao, L. (2007), Capital budgeting practices: A comparative study of the Netherlands and China, International Business Review, 16 (2007) 630-654.

6. Laitinen, E.K. (2001), Management accounting change in small technology companies: Towards a mathematical model of the technology firm, Management Accounting Research, 12 (2001) 507-541.

7. Lam, K.C., Wang, D., Lam, M.C.K. (2007), The capital budgeting evaluation practices (2004) of building contractors in Hong Kong, International Journal of Project Management, 25 (2007) 824-834.

8. Payne, J.D., Heath, W.C., Gale, L.R. (1999), Comparative financial practice in the US and Canada: Capital budgeting and risk assessment techniques, Financial Practice and Education, 9(1) (1999) 16-24.

9. Pike, R. (1996), A longitudinal survey on capital budgeting practices, The Journal of Business Finance and Accounting, 23(1) (1996) 79-92.

10. Ryan, P.A., Ryan, G.P. (2002), Capital budgeting practices of the Fortune 1000: how have things changed?, Journal of Business and Management, 8(4) (2002) 355-364.

11. Silvola (2006), Low-intensity R\&D and capital budgeting decisions in it firms, Advances in Management Accounting, 15 (2006) 21-49.

12. Truong, L.G., Partington, G., Peat, M. (2005), Cost of capital estimation and capital budgeting practice in Australia, Working Paper, University of Sydney, Sydney. 